\title{
Study of the Physicochemical Properties and Anti-biofilm Effects of Synthesized Zinc Oxide Nanoparticles Using Artemisia Plant
}

\author{
Sahar Galedari, Maryam Teimouri ${ }^{*}$ \\ Department of Biology, Roudehen Branch, Islamic Azad University, Roudehen, Iran
}

\author{
*Correspondence to \\ Maryam Teimouri, \\ Email: teimourimaryam93@gmail. \\ com
}

Received April 24, 2020

Accepted July 1, 2020

Published online 30 Septemeber 2020

\begin{abstract}
Introduction: Recently, the biosynthesis of nanoparticles (NPs) using medicinal plants has attracted the attention of researchers due to their low cost and environmental compatibility. The aim of this study was to determine the anti-biofilm effects of zinc oxide ( $\mathrm{ZnO}$ )-NPs synthesized using the Artemisia plant extract on the clinical samples of Pseudomonas aeruginosa.

Methods: In this experimental study, the alcoholic extract of Artemisia was prepared using the Soxhlet extraction method to synthesize ZnO-NPs. Then, the physical and chemical structures of the NPs were investigated using transmission electron microscopy (TEM), scanning electron microscopy (SEM), and ultraviolet/visible (UV-Vis) techniques. In addition, the gene expression of $n d v B$ was analyzed by the polymerase chain reaction method. Finally, anti-biofilm and antimicrobial effects were evaluated using the minimum inhibitory concentration test and microtiter plate assay.

Results: The antimicrobial results showed that ZnO-NPs had a spherical structure approved by the UV-Vis test. Further, ZnO-NPs had inhibitory effects on biofilm formation by $P$. aeruginosa strains. The results demonstrated that $\mathrm{ZnO}-\mathrm{NPs}$ were effective on the isolations at the lowest and highest viscosities of 3.125 and $100 \mathrm{mg} / \mathrm{mL}$, respectively.

Conclusion: The biosynthesis of ZnO-NPs using the Artemisia plant extract is low cost and easy. Moreover, these NPs can be used as a drug with antimicrobial and anti-biofilm effects.

Keywords: ZnO-NPs, Artemisia, Pseudomonas Aeruginosa, Anti-biofilm
\end{abstract}

\begin{abstract}
Please cite this article as follows: Galedari S, Teimouri M. Study of the Physicochemical Properties and Antibiofilm Effects of Synthesized Zinc Oxide Nanoparticles Using Artemisia Plant . Int J Basic Sci Med. 2020;5(3):101107. doi: 10.34172 ijbms.2020.18.
\end{abstract}

\section{Introduction}

Nano-biotechnology deals with a variety of material structures with dimensions up to the size range of $1-100 \mathrm{~nm}$. In recent decades, microbial nanobiotechnology, especially zinc oxide nanoparticles ( $\mathrm{ZnO}$ NPs), has provided promising prospects for combating various infectious diseases. ${ }^{1,2}$

$\mathrm{ZnO}-\mathrm{NPs}$ offer a unique solution for medical applications and their function is controlled by geometric and optical properties. In addition, they are subjected to biomedical studies and applications including genetics, biosensor development, clinical chemistry, laser phototherapy of cancer cells and tumors, photothermal therapy, photodynamic therapy, and targeted drug delivery. Further, NPs are among the materials that have received special attention due to their special physicochemical properties because they
\end{abstract}

are chemically stable, non-toxic, and easily functional. Nowadays, numerous methods have been developed for NP synthesis. ${ }^{3,4}$

For instance, green chemistry is an emerging method for designing and synthesizing pharmaceutical organic compounds and has an easy protocol while being effective in treating various diseases. One of the advantages of compounds synthesized by green chemistry is their biocompatibility and biodegradability over chemicals synthesized by classical methods. Furthermore, these compounds typically have lower production costs. ${ }^{5}$

Secondary metabolites, enzymes, proteins, or other reducing agents play an essential role in the preparation of metal NPs by plants. Moreover, the bioaccumulation of NPs depends on the presence of enzymes and proteins that are involved in their preparation. The

(C) 2020 The Author(s); Published by Zabol University of Medical Sciences. This is an open-access article distributed under the terms of the Creative Commons Attribution License (http://creativecommons.org/licenses/by/4.0), which permits unrestricted use, distribution, and reproduction in any medium, provided the original work is properly cited. 
recovery of NPs from plant tissues requires enzymes to destroy cellulose, which is exhausting and expensive. Therefore, using plant extractions for the low and large scale processing of different metal NPs is considered as an easy and convenient alternative to chemical and physical methods. The geranium (i.e., leaf, stem, and root extracts) was first used to produce extracellular NPs. ${ }^{6-8}$ Arunachalam et al reported the biosynthesis of $\mathrm{Zn}$-byions using geranium leaf extraction. They also produced triangular and spherical $\mathrm{Zn}$ particles using lemon extraction. ${ }^{9}$

Artemisia is one of the largest genera of the family Asteraceae or Compositae and is rich in substances that have a variety of anti-inflammatory, anti-tumor, antioxidant, and anti-proliferative effects. Additionally, this genus contains high amounts of terpenoids and flavonoids, and more than 160 flavonoid compounds have been extracted from this genus. ${ }^{10,11}$

Treating bacterial infections have been problematic in recent decades due to their resistance to antibiotics, and the $21^{\text {st }}$ century is called the century of antibiotic failure. Studies on different bacteria have shown that the presence of $\mathrm{ZnO}$-NPs can have a significant role in controlling bacterial biofilms and thus preventing bacterial viability. Pseudomonas aeruginosa is a gram-negative bacillus and an opportunistic bacterium with pathogenic potency in humans, animals, and plants. This bacterium is one of the most important causes of nosocomial infections in a wide range of immunocompromised patients with malignancies, cystic fibrosis, burns, and the like. In addition, different strains of this bacterium can cause similar symptoms and death in animals with the weakened immune system. Bacterial biofilm formation confers the organism resistant to many antibiotics, thus more research is needed to find suitable alternatives to antibiotics. ${ }^{12-14}$

In this regard, this study aimed to produce $\mathrm{ZnO}$ NPs with plausible physicochemical properties using the Artemisia extract. Then, the study investigated the physical and chemical properties and antimicrobial effects of the synthesized $\mathrm{ZnO}$-NPs on the clinical isolates of $P$. aeruginosa.

\section{Materials and Methods \\ Plant Collection and Extraction}

The Artemisia plant was obtained from the Bank of Iran Biological Reserve Center and then approved by the botanical section with the herbarium number of 1342 . The aerial parts of the plant were air-dried and then completely dried in the shade for extraction. The leaves were thoroughly powdered by an electric milking machine and kept in glass containers. In addition, the powder was extracted using the Soxhlet extraction method. Next, 50 $\mathrm{g}$ of the plant leaf powder was added to $500 \mathrm{~mL}$ of the methanol solvent. The extraction was conducted for 12 hours, and finally, the solvent was removed by a rotary evaporator (Rv10 digital, German).

The obtained solid powder by distillation was doubled in volume and the extract was stored at $4^{\circ} \mathrm{C}$ until use for $\mathrm{ZnO}-\mathrm{NPs}$ synthesis.

\section{Green Synthetic Route of Zinc Oxide Nanoparticles}

The metal ions were synthesized by the Artemisia extract through high purity synthesis in different sizes. Further, $\mathrm{ZnO}$-NPs were synthesized by adding different volumes of the Artemisia extract to various viscosities of HACUI4 (purchased from Merck) salt under different stirring conditions. Two hours after the reaction, the precipitate was washed three times with distilled water $(13000 \mathrm{rpm}$ for 20 minutes). The final washings were performed with ethanol and the resulting product was incubated at $75^{\circ} \mathrm{C}$ for 2 hours.

\section{Characterization of Zinc Oxide Nanoparticles Dynamic Light Scattering}

The particle size distribution was determined by Malvern Zetasizer (Nano ZS) at room temperature and the angle of $90^{\circ}$. To evaluate the above-mentioned parameters, the device was calibrated based on the aqueous phase (RI: 1.3), and then the synthesized NPs were passed through a syringe filter with a size of $0.22 \mathrm{~mm}$.

\section{Transmission Electron Microscopy}

To investigate the morphology and confirm the $\mathrm{ZnO}$ NPs size, a drop of the suspension sample was placed on the carbon film grid and, after being dried at laboratory temperature, it was imaged using a transient electron microscope (LEO 906, Zeiss $100 \mathrm{kV}$ ) with the accelerator voltage of $120 \mathrm{kV}$.

\section{Scanning Electron Microscopy}

Scanning electron microscopy (SEM) images and pointto-point studies were carried out to investigate the size and morphology of NPs after covering with $\mathrm{Zn}$ at a voltage below $30 \mathrm{kV}$ under vacuum pressure $\left(10^{-5}\right.$ Torr $)$ using SEM. Then, $\mathrm{ZnO}$-NPs were dissolved in water and the resulted suspension was subjected to SEM imaging.

\section{Collecting Clinical and Microbiological Samples}

In this study, 50 suspected $P$. aeruginosa specimens were collected from 50 patients who referred to Imam Khomeini hospital in Tehran. For this purpose, informed consent forms were from all patients, and the purpose of the study was explained to them. The collected samples included urine, wound, cerebrospinal fluid, blood, and sputum which were cultured on eosin-methylene blue and MacConkey agar medium after their transfer to the microbiology research laboratory of Roudehen Azad University. After the preparation of slides and the observation of Gram-negative bacilli, routine biochemical tests such as the culture in sulfur indole motility, triple sugar iron, and methyl red/Voges-Proskauer media, as 
well as citrate media and oxidase test were performed to confirm $P$. aeruginosa. Then, the bacteria were studied and stored in trypticase soy broth and glycerol at $70^{\circ} \mathrm{C}$ for subsequent tests.

In addition, antibiotic (Bio-Rad disks) resistance was assessed by the disk diffusion method (Kirby-Bauer method) based on the Clinical and Laboratory Standards Institute (CLSI) (100) in which 0.5 McFarland equivalent microbial suspension was cultured in the MuellerHilton agar medium. The applied standard antibiotic discs included ciprofloxacin $(5 \mu \mathrm{g})$, chloramphenicol $(30 \mu \mathrm{g})$, polymyxin $(300 \mu \mathrm{g})$, erythromycin $(15 \mu \mathrm{g})$, meropenem $(10 \mu \mathrm{g})$, ceftazidime $(30 \mu \mathrm{g})$, cefotaxime $(30$ $\mu \mathrm{g})$, tetracycline $(30 \mu \mathrm{g})$, and tobramycin $(10 \mu \mathrm{g})$ on the Mueller-Hinton agar medium with the sterile single-sided swab test. The space between the disks was 20 and $16 \mathrm{~mm}$ from the wall, and incubation lasted for 18-24 hours at $37^{\circ} \mathrm{C}$. Eventually, the results were evaluated by measuring the growth zone diameter and comparing them with a standard table.

\section{Phenotypic Evaluation of Biofilm Formation}

The applied method in phenotypic testing was the one that was used by Freeman et al. In this method, Congo red agar culture medium was utilized for 24 hours at $37^{\circ} \mathrm{C} .^{15}$

\section{PCR and Electrophoresis}

For DNA extraction, bacteria were cultured in the LuriaBertani broth medium for 12 hours, and the Bio Flux kit was used for extraction. ${ }^{15}$ To isolate PCR bands, estimate the molecular weight of the bands, and to observe the quality of the purified DNA, they were subjected to electrophoresis (agarose gel 2\%) after ethidium bromide staining, and finally, visualized by a transilluminator in a dark room with a UV lamp at $254 \mathrm{~nm}$. In this wavelength, DNA has the highest optical absorption. Eventually, the gels were photographed for closer examination.

\section{Detection of the $n d v B$ Gene}

The $n d v B$ affects the expression of multiple genes that are involved in biofilm formation. This gene was amplified using the primers listed in Table 1.

\section{Evaluation of the Antimicrobial Activity of $\mathrm{ZnO}$-NPs by} the Minimum Inhibitory Concentration Method

The minimum inhibitory concentration (MIC) test was performed using the microplate dilution method according to the CLSI standards (CLSI 2017) to check sensitivity to antibiotics. The inoculation of microorganisms was

Table 1. The Sequences of Primers Used to Amplify the $n d v B$ Gene

\begin{tabular}{lllc}
\hline Gene & Primer & Nucleotide Sequence & $\begin{array}{c}\text { Product } \\
\text { Size (bp) }\end{array}$ \\
\hline \multirow{n}{*}{$\boldsymbol{d} \boldsymbol{B} \boldsymbol{B}$} & $\begin{array}{l}\text { Forward } \\
\text { Reverse }\end{array}$ & F 5' 5 $^{\prime}$ 'TTCTTCTCTCTGCAGCAATG - $3^{\prime}$ & 153 \\
\hline
\end{tabular}

obtained after 12 hours of culturing in the liquid medium to obtain standard McFarland turbidity. The NPs were prepared at the concentrations of $3.125,6.25,12.5,25$, 50 , and $100 \mu \mathrm{g} / \mathrm{mL}$. Subsequently, 96 well plates were provided by a $95 \mu \mathrm{L}$ dispenser from the Mueller-Hinton broth medium and $5 \mu \mathrm{L}$ microbial inoculum inside each well. Next, $100 \mu \mathrm{L}$ of NPs with different concentrations were poured into the wells. The bottom well containing $95 \mu \mathrm{L}$ of the Mueller-Hinton broth medium and $5 \mu \mathrm{L}$ of microbial inoculation per row were used as controls. The obtained volume in all wells was $200 \mu \mathrm{L}$. Ultimately, the plate was stirred on the shaker for 60 seconds and then incubated at $37^{\circ} \mathrm{C}$ for 24 hours and examined again. Each test was repeated three times.

\section{Phenotypic Evaluation of Anti-biofilm Effects}

The microliter definition method was used to study the quantitative effects of $\mathrm{ZnO}-\mathrm{NPs}$ on the biofilm. ${ }^{15}$ To this end, $50 \mu \mathrm{L}$ of non-lethal concentrations of $\mathrm{ZnO}$-NPs were incubated at $37^{\circ} \mathrm{C}$ for 24 hours after 24 hours of culturing of each isolate and bringing the opacity to about 0.5 McFarland (the optical absorption of about 0.08-0.1 at $625 \mathrm{~nm}$ wavelengths). Bacteria attached to the wall were immobilized with $250 \mu \mathrm{L}$ of $96 \%$ ethanol after 15 minutes. After the plates were dried, $200 \mu \mathrm{L}$ of the crystal violet was added and incubated for 15 minutes. Then, the biofilm was evaluated by adding $200 \mu \mathrm{L}$ of acetic acid 33\% to each well, and finally, its absorption at $492 \mathrm{~nm}$ wavelength was read by an enzyme-linked immunosorbent assay reader.

\section{Results}

The reaction was carried out at room temperature after adding the dried plant extract to the $\mathrm{Zn}$ salt solution, and color change showed $\mathrm{ZnO}$-NP formation (Figure 1). The resulted brown solution was analyzed by dynamic light scattering (DLS), SEM, transmission electron microscopy (TEM), and ultraviolet/visible (Uv-Vis) techniques. Figure 2 displays the maximum absorption rate of solutions containing ZnO-NPs at $322 \mathrm{~nm}$. The DLS study showed that the average size of lipid NPs containing the essence
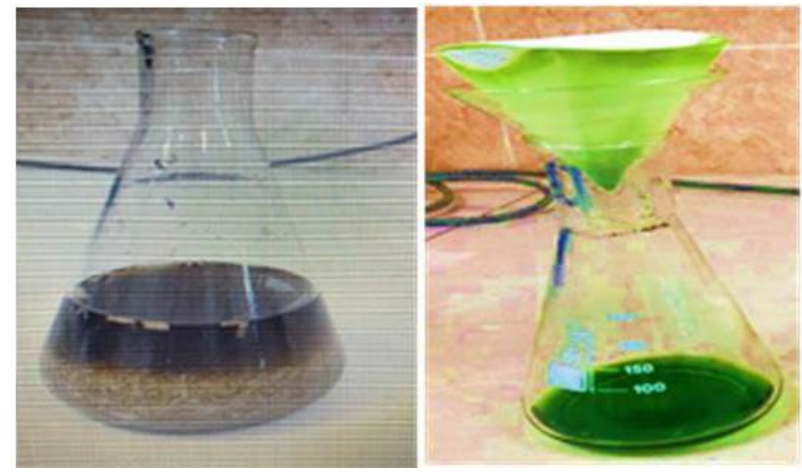

Figure 1. Color Change During the Synthesis of ZnO-NPs by the Artemisia Plant Extract.

Note. ZnO-NPs: Zinc oxide nanoparticles. 


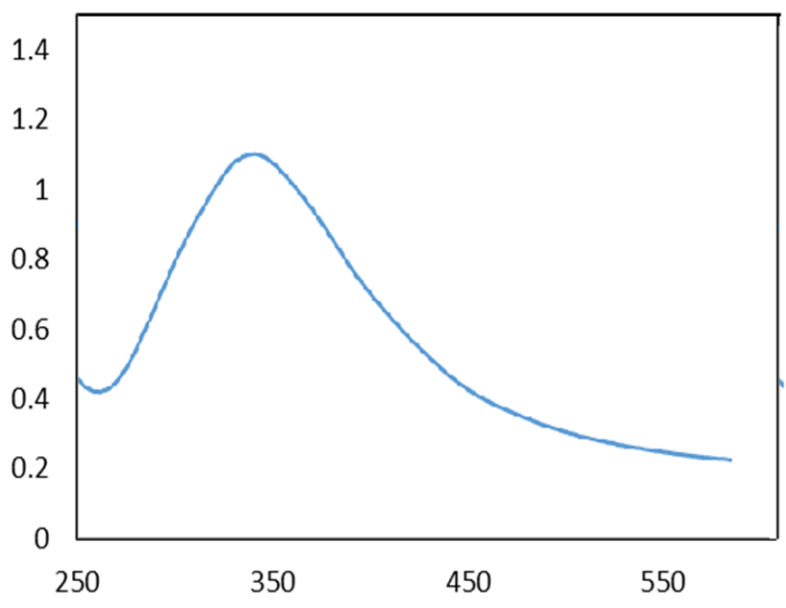

Figure 2. Ultraviolet/visible Spectroscopy of ZnO-NPs Synthesized by the Artemisia Plant Extract.

Note. ZnO-NPs: Zinc oxide nanoparticles. As shown, the UV absorption of the synthesized ZnO-NPs was between 250 and 550 $\mathrm{nm}$, and the maximum absorption was at the wavelength of 320 $\mathrm{nm}$.

of $\mathrm{ZnO}$-NPs was $78.86 \mathrm{~nm}$ (Figure 3). TEM image results demonstrated that the average size of the NPs was $17 \mathrm{~nm}$ (Figure 4). Further, the structure of the NPs was observed to be spherical as demonstrated by SEM microscopy (Figure 5).

\section{Isolation of Pseudomonas aeruginosa Strains}

In this study, 50 clinical specimens suspected to be $P$. aeruginosa based on green lactose negative colonies were isolated and 20 strains were selected by microscopic and biochemical tests. The concordant agar medium was used for the phenotype evaluation of the biofilm. Biofilm forming bacteria produced black colonies while nonbiofilm strains remained the same as the original red. Moreover, all 20 clinical strains were positive for biofilm formation. The molecular analysis of the presence of the biofilm-producing gene $(n d v B)$ was performed, which resulted in $153 \mathrm{bp}$ bands according to the designed primer. Figure 6 shows that the $n d v B$ gene was present in all strains.

The results revealed that $\mathrm{ZnO}-\mathrm{NPs}$ were effective on the isolates at the lowest viscosity of $3.125 \mathrm{mg} / \mathrm{mL}$ and the highest viscosity of $100 \mathrm{mg} / \mathrm{mL}$. Additionally, the microliter plate method was used to quantitatively study the anti-biofilm effects of $\mathrm{ZnO}$-NPs. Based on the results of this test, not all strains of the sub-MIC of NPs had biofilm formation ability (Figure 7).

\section{Discussion}

NPs have shown the potential for reducing the adverse effects of nosocomial infectious on humans health. The bacteria are considered as the most important contributing factors to nosocomial infections. These organisms act in various ways to create pollution and maintain their stability in the environment. One of the most important of these methods is forming biofilms that play a key role in creating bacterial stability in the environment by converting the bacterial planktonic form to a fixed form. For example, $P$. aeruginosa in the planktonic form is less resistant to ceftriaxone antibiotic compared to the fixed biofilm form. ${ }^{14}$ In the biofilm structure, suitable nutrients are provided to the bacteria for growth due to selective transitional openings. ${ }^{16}$

Mohsenipour et al reported that the Euphorbia hebecarpa ethanolic extract better inhibited the planktonic forms of bacteria in comparison to methanolic extracts. ${ }^{17}$ However, these pores appear to be somewhat impermeable to antibiotics, which may be one of the main causes of bacterial resistance and biofilm stability.

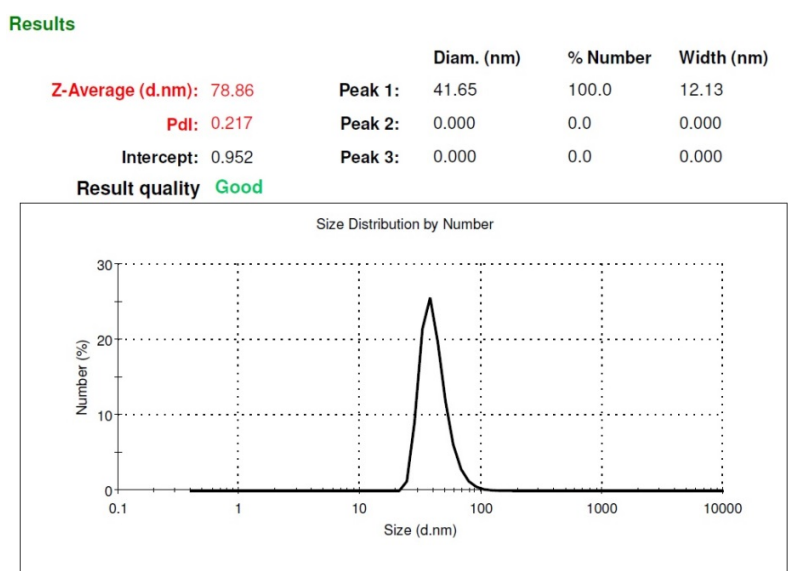

Figure 3. An Example of the Spectrum Obtained From Particle Size Determination and the Dispersion Index in ZnO-NPs Synthesized by the Artemisia Plant Extract.

Note. ZnO-NPs: Zinc oxide nanoparticles.

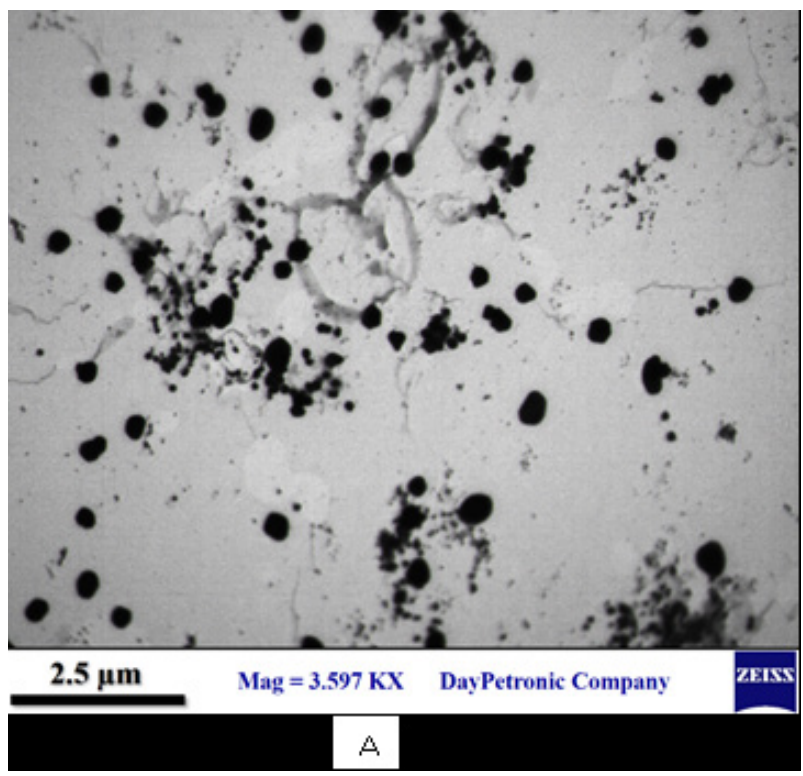

Figure 4. TEM Microscope Image of ZnO-NPs Produced by the Artemisia Plant Extract Showing the Spherical Shape of NPs.

Note. TEM: Transmission electron microscopy; ZnO-NPs: ZnONPs: Zinc oxide nanoparticles. 


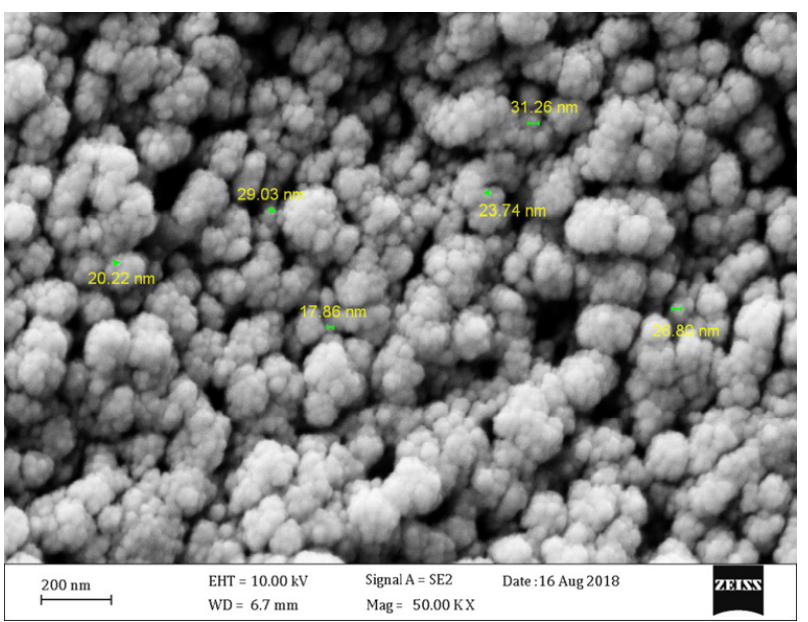

Figure 5. SEM Microscope Image of ZnO-NPs Produced by the Artemisia Plant Extract.

Note. TEM: Transmission electron microscopy; ZnO-NPs: Zinc oxide nanoparticles.

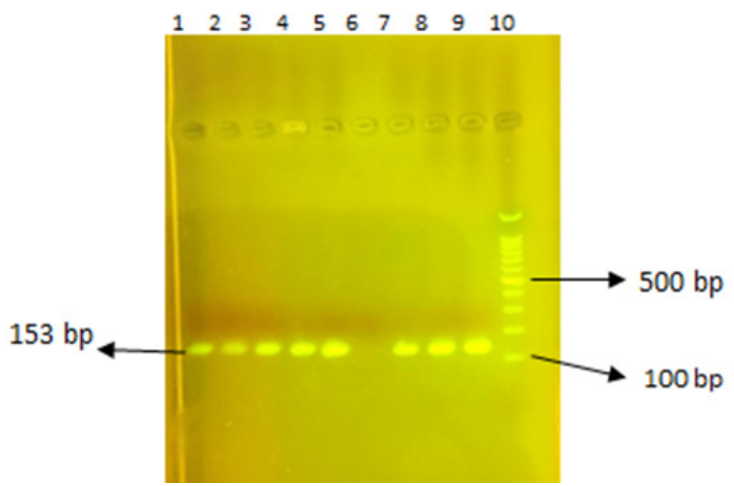

Figure 6. Electrophoresis of the $n d v B$ Gene Resulting in 153 bp Bands on 1\% Agarose Gel.

Since the biofilm plays the first and most important role against antibiotics and other drugs, using $\mathrm{ZnO}-\mathrm{NPs}$ may be effective in destructing these structures. Therefore, the identification of biofilm-producing bacteria and the study of the effects of $\mathrm{ZnO}$-NPs on biofilm expression have been the principles that many researchers have been trying to prove and apply to these particles against bacterial biofilms. ${ }^{18}$ Various chemical solvents have been used to synthesize $\mathrm{ZnO}-\mathrm{NPs}$ in recent years. For example, Iravani et al used triethanolamine as a reducing agent to produce the NPs of about $40 \mathrm{~nm}$ in size and then investigated the antimicrobial activity of the produced particles. ${ }^{19}$ Our results also showed that $\mathrm{ZnO}-\mathrm{NPs}$ were effective on the isolations at the lowest and highest viscosities of 3.125 and $100 \mathrm{mg} / \mathrm{mL}$, respectively. In another study, Horna et al evaluated the inhibitory effects of bacteria with a high frequency of the exoU+/exoS+ genotype associated with multidrug-resistant, including $P$. aeruginosa, ampicillinresistant Escherichia coli, and erythromycin-resistant Streptococcus pyogenes. They observed that nanotubes had a remarkable bacteriostatic effect on these bacteria. ${ }^{20}$
Different species of Artemisia contain high concentrations of antimicrobial compounds in addition to antioxidants. ${ }^{7}$ It is remarkable that this herb is able to maintain the natural microbial flora of the body. Various reports demonstrated that the antimicrobial activity of Artemisia is exerted by various mechanisms including interference with the proton transport chain in mitochondria, ${ }^{21}$ the disruption of proteins, interference with membrane function, ${ }^{22}$ and the inhibition of the sarcoplasmic reticulum calcium pump. ${ }^{23}$ Similarly, Ravindra et al studied the antibacterial activity of curcumin-loaded $\mathrm{ZnO}-\mathrm{NPs}$ and reported a high antibacterial level. ${ }^{24}$

The present study examined the MIC of $\mathrm{ZnO}-\mathrm{NPs}$ against the clinical strains of $P$. aeruginosa, and the results showed that $\mathrm{ZnO}-\mathrm{NPs}$ had significant lethal effects with the concentrations of $3.125-100 \mu \mathrm{g} / \mathrm{mL}$. The results further revealed that $\mathrm{ZnO}-\mathrm{NPs}$ at the lowest concentration of $3.125 \mu \mathrm{g} / \mathrm{mL}$ and the highest concentration of $100 \mu \mathrm{g} / \mathrm{mL}$ were effective on the isolates. Accordingly, our findings confirmed the dose-dependent antibacterial effects of $\mathrm{ZnO}-\mathrm{NPs}$ against this bacterium. Some studies linking the antibacterial effects of $\mathrm{ZnO}$ NPs against bacteria with high drug resistance (i.e., $P$. aeruginosa, ampicillin-resistant E. coli, and ciprofloxacinresistance Klebsiella) represented the bacteriostatic effect by $\mathrm{ZnO}-\mathrm{NPs} .{ }^{18}$ Likewise, Arunachalam et al evaluated the antimicrobial effects of $\mathrm{ZnO}-\mathrm{NPs}$ against bacteria such as Staphylococcus aureus and E. coli and reported that $\mathrm{ZnO}-\mathrm{NP}$ activity was concentration-dependent and had stronger antibacterial effects against Gram-negative bacteria compared to Gram-positive ones. This may highlight the difference between these two groups of bacteria regarding their cell wall structure. ${ }^{9}$ In their study, Agnihotri et al investigated the impact of $\mathrm{ZnO}-\mathrm{NPs}$ on $E$.

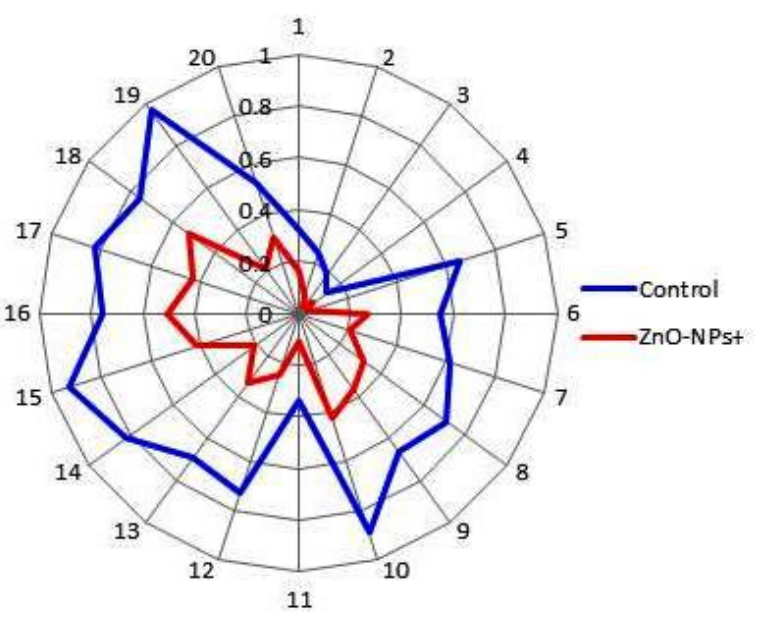

Figure 7. Quantitative Study of Biofilm Production in Strains Affected by ZnO-NPs.

Note. ZnO-NPs: Zinc oxide nanoparticles. 
coli, P. aureus, and Bacillus subtilis. Based on their finding, the lowest MICs of $\mathrm{ZnO}$-NPs on the three strains were 3, 2 , and $19 \mu \mathrm{g} / \mathrm{mL}$, respectively, with an average diameter of $7 \mathrm{~nm}$. Additionally, the lowest inhibitory concentrations were reported for nano-medium with a diameter of $70 \mathrm{~nm}$ for E. coli and P. aureus as 34 and $25 \mu \mathrm{g} / \mathrm{mL}$, respectively. ${ }^{25}$ Gupta at al reported similar results demonstrating the significant antibacterial activity of $\mathrm{ZnO}-\mathrm{NPs}$ against $S$. aureus MTCC 9760, S. pyogenes MTCC 1926, B. cereus MTCC 430, P. aeruginosa MTCC 424, P. mirabilis MTCC 3310, and E. coli MTCC 40. In addition, the synthesized $\mathrm{ZnO}-\mathrm{NPs}$ showed antibacterial efficacy against both Gram-positive and Gram-negative pathogens. ${ }^{26}$

Further, Ansari et al found the ability of biofilm formation by Pseudomonas strains using the Congo red agar culture, and the results of SEM revealed that $\mathrm{ZnO}-\mathrm{NPs}$ prevented the growth of bacteria and biofilm formation. ${ }^{27}$ Similarly, Chikkanna et al studied the inhibitory effect of $\mathrm{ZnO}-\mathrm{NPs}$ and chlorhexidine on biofilm formation by $P$. aeruginosa strains. ${ }^{28}$ The results of a recent study also showed that this compound had anti-biofilm properties and could destroy the ability to form biofilms. ${ }^{26}$ Some previous studies reported the anti-biofilm effects of $\mathrm{NPs}^{29,30}$ indicating that the highest MIC values of the essential oil were determined $100 \mathrm{ppm}$ against $E$. coli, and the highest MIC value for K. pneumoniae was 250 ppm. $^{31}$

The extraordinary ability of $\mathrm{Zn}$ as an antimicrobial agent has encouraged many researchers to use Zn-NPs in anti-microbial research. ${ }^{32}$ For instance, Garza-Cervantes et al compared the antimicrobial activity of $\mathrm{ZnO}-\mathrm{NPs}$ and several antimicrobial compounds against biofilmproducing $P$. aeruginosa strains. The results of the recent study showed that using $\mathrm{ZnO}-\mathrm{NPs}$ in combination with antimicrobial agents reduced biofilm formation, increased treatment efficacy, and prevented the formation of resistant strains. ${ }^{33}$ Finally, Tiwari et al studied the effects of $\mathrm{ZnO}-\mathrm{NPs}$ as antibacterial agents and demonstrated that $\mathrm{ZnO}-\mathrm{NPs}$ reduced the growth of microbial agents. ${ }^{34}$

\section{Conclusion}

Various investigations showed that $\mathrm{ZnO}-\mathrm{NPs}$ have a remarkable ability to inhibit bacterial infectious diseases. More precisely, $\mathrm{ZnO}-\mathrm{NPs}$ had inhibitory effects on $P$. aeruginosa strains. Overall, they can be used as antimicrobial and anti-biofilm drugs.

\section{Ethical Approval}

The study protocol was approved by the Ethics Committee of Islamic Azad university of Roudehen Branch, Roudehen, Iran (Code No: 113305609710002).

\section{Conflict of Interest Disclosure}

There is no conflict of interests in this study.

\author{
Informed Consent \\ Not applicable.
}

Funding/Support

None.

\section{Authors' Contribution}

MT: Designing the study and conducting all testes and data collection, contributing to writing and editing the manuscript and approving the final version of the manuscript.; SG: conducting all testes and data collection Participating in data collection and analysis.

\section{Acknowledgments}

We would like to thank the Department of Biology, Roudehen Branch, Islamic Azad University, Roudehen, Iran for the support during this study.

\section{References}

1. Rahman K, Khan SU, Fahad S, et al. Nano-biotechnology: a new approach to treat and prevent malaria. Int J Nanomedicine. 2019;14:1401-1410. doi:10.2147/ijn. s190692

2. Gupta S, Kushwah T, Vishwakarma A, Yadav S. Optimization of $\mathrm{ZnO}-\mathrm{NPs}$ to investigate their safe application by assessing their effect on soil nematode Caenorhabditis elegans. Nanoscale Res Lett. 2015;10(1):1010. doi:10.1186/ s11671-015-1010-4

3. Dimkpa CO, Andrews J, Fugice J, et al. Facile coating of urea with low-dose $\mathrm{ZnO}$ nanoparticles promotes wheat performance and enhances $\mathrm{Zn}$ uptake under drought stress. Front Plant Sci. 2020;11:168. doi:10.3389/fpls.2020.00168

4. Zhou Y, Fang X, Gong Y, et al. The interactions between $\mathrm{ZnO}$ nanoparticles (NPs) and $a$-linolenic acid (LNA) complexed to BSA did not influence the toxicity of $\mathrm{ZnO}$ NPs on HepG2 cells. Nanomaterials (Basel). 2017;7(4). doi:10.3390/nano7040091

5. de Marco BA, Rechelo BS, Tótoli EG, Kogawa AC, Salgado HRN. Evolution of green chemistry and its multidimensional impacts: a review. Saudi Pharm J. 2019;27(1):1-8. doi:10.1016/j.jsps.2018.07.011

6. Aderibigbe BA. Metal-based nanoparticles for the treatment of infectious diseases. Molecules. 2017;22(8). doi:10.3390/molecules 22081370

7. Pooladi M, Rezaei-Tavirani M, Hashemi M, et al. The study of "Dihydropyrimidinase related proteins (DRPs)" expression changes influence in malignant astrocytoma brain tumor. Iran J Cancer Prev. 2014;7(3):130-136.

8. Wang C, Lu J, Zhou L, et al. Effects of long-term exposure to zinc oxide nanoparticles on development, zinc metabolism and biodistribution of minerals $(\mathrm{Zn}, \mathrm{Fe}, \mathrm{Cu}, \mathrm{Mn})$ in mice. PLoS One. 2016;11(10):e0164434. doi:10.1371/journal. pone. 0164434

9. Arunachalam R, Dhanasingh S, Kalimuthu B, Uthirappan M, Rose C, Mandal AB. Phytosynthesis of silver nanoparticles using Coccinia grandis leaf extract and its application in the photocatalytic degradation. Colloids Surf B Biointerfaces. 2012;94:226-230. doi:10.1016/j. colsurfb.2012.01.040

10. Katinas L, Hernández MP, Arambarri AM, Funk VA. The origin of the bifurcating style in Asteraceae (Compositae). Ann Bot. 2016;117(6):1009-1021. doi:10.1093/aob/ 
mcw033

11. Bakand S, Hayes A, Dechsakulthorn F. Nanoparticles: a review of particle toxicology following inhalation exposure. Inhal Toxicol. 2012;24(2):125-135. doi:10.3109/08958378.2 010.642021

12. Firouzi-Dalvand L, Nowroozi J, Akhvan-Sepahi A, Pooladi M, Hooshiyar M. Presence of exoU and exoS genes in Pseudomonas aeruginosa isolated from urinary tract infections. Infect Epidemiol Med. 2016;2(2):8-11. doi:10.18869/modares.iem.2.2.8

13. Bédard E, Prévost M, Déziel E. Pseudomonas aeruginosa in premise plumbing of large buildings. Microbiologyopen. 2016;5(6):937-956. doi:10.1002/mbo3.391

14. Firouzi-Dalvand L, Pooladi M. Identification of exoS, exoU genes in Pseudomonas aeruginosa. J Paramed Sci. 2014;5(4):89-95. doi:10.22037/jps.v5i4.7825

15. Freeman DJ, Falkiner FR, Keane CT. New method for detecting slime production by coagulase negative staphylococci. J Clin Pathol. 1989;42(8):872-874. doi:10.1136/jcp.42.8.872

16. Singh J, Dutta T, Kim KH, Rawat M, Samddar P, Kumar P. 'Green' synthesis of metals and their oxide nanoparticles: applications for environmental remediation. J Nanobiotechnology. 2018;16(1):84. doi:10.1186/s12951018-0408-4

17. Mohsenipour Z, Hassanshahian M. Antibacterial activity of Euphorbia hebecarpa alcoholic extracts against six human pathogenic bacteria in planktonic and biofilm forms. Jundishapur J Microbiol. 2016;9(6):e34701. doi:10.5812/ jjm.34701

18. Banerjee S, Jha HC, Robertson ES. Regulation of the metastasis suppressor Nm23-H1 by tumor viruses. Arch Pharmacol. 2014;15(2):587-90.

19. Iravani S, Korbekandi H, Mirmohammadi SV, Zolfaghari B. Synthesis of silver nanoparticles: chemical, physical and biological methods. Res Pharm Sci. 2014;9(6):385-406.

20. Horna G, Amaro C, Palacios A, Guerra H, Ruiz J. High frequency of the exoU+/exoS+ genotype associated with multidrug-resistant "high-risk clones" of Pseudomonas aeruginosa clinical isolates from Peruvian hospitals. Sci Rep. 2019;9(1):10874. doi:10.1038/s41598-019-47303-4

21. Wang J, Huang L, Li J, et al. Artemisinin directly targets malarial mitochondria through its specific mitochondrial activation. PLoS One. 2010;5(3):e9582. doi:10.1371/ journal.pone.0009582

22. Brisibe EA, Umoren UE, Brisibe F, et al. Nutritional characterisation and antioxidant capacity of different tissues of Artemisia annua L. Food Chem. 2009;115(4):1240-1246. doi:10.1016/j.foodchem.2009.01.033

23. Mamatova AS, Korona-Glowniak I, Skalicka-Woźniak K, et al. Phytochemical composition of wormwood (Artemisia gmelinii) extracts in respect of their antimicrobial activity. BMC Complement Altern Med. 2019;19(1):288. doi:10.1186/s12906-019-2719-x

24. Singh RP, Shukla VK, Yadav RS, Sharma PK, Singh PK, Pandey AC. Biological approach of zinc oxide nanoparticles formation and its characterization. Adv Mater Lett. 2011;2(4):313-317. doi:10.5185/amlett.indias.204

25. Agnihotri S, Dhiman NK. Development of nanoantimicrobial biomaterials for biomedical applications. In: Tripathi A, Melo J, eds. Advances in Biomaterials for Biomedical Applications. vol 66. Singapore: Springer; 2017:479-545. doi:10.1007/978-981-10-3328-5_12

26. Gupta M, Tomar RS, Kaushik S, Mishra RK, Sharma D. Effective antimicrobial activity of green $\mathrm{ZnO}$ nano particles of Catharanthus roseus. Front Microbiol. 2018;9:2030. doi:10.3389/fmicb.2018.02030

27. Ansari MA, Murali M, Prasad D, et al. Cinnamomum verum bark extract mediated green synthesis of $\mathrm{ZnO}$ nanoparticles and their antibacterial potentiality. Biomolecules. 2020;10(2). doi:10.3390/biom10020336

28. Chikkanna MM, Neelagund SE, Rajashekarappa KK. Green synthesis of zinc oxide nanoparticles (ZnO NPs) and their biological activity. SN Appl Sci. 2018;1(1):117. doi:10.1007/ s42452-018-0095-7

29. Hamayeli H, Hassanshahian M, Askari Hesni M. The antibacterial and antibiofilm activity of sea anemone (Stichodactyla haddoni) against antibiotic-resistant bacteria and characterization of bioactive metabolites. Int Aquat Res. 2019;11(1):85-97. doi:10.1007/s40071-019-0221-1

30. Hamayeli H, Namaki Shoshtari A, Hassanshahian M, Askari Hesni M. Study the antimicrobial activity of six marine sponges and three parts of sea anemone on Candida albicans. J Coast Life Med. 2016;4(8):612-615. doi:10.12980/jclm.4.2016J6-76

31. Hassanshahian M, Bayat Z, Saeidi S, Shiri Y. Antimicrobial activity of Trachyspermum ammi essential oil against human bacterial. Int J Adv Biol Biomed Res. 2014;2(1):1824.

32. Pinho AR, Rebelo S, Pereira ML. The impact of zinc oxide nanoparticles on male (in) fertility. Materials (Basel). 2020;13(4). doi:10.3390/ma13040849

33. Garza-Cervantes JA, Escárcega-González CE, Barriga Castro ED, et al. Antimicrobial and antibiofilm activity of biopolymer-Ni, Zn nanoparticle biocomposites synthesized using R. mucilaginosa UANL-001L exopolysaccharide as a capping agent. Int J Nanomedicine. 2019;14:2557-2571. doi:10.2147/ijn.s196470

34. Tiwari V, Mishra N, Gadani K, Solanki PS, Shah NA, Tiwari M. Mechanism of anti-bacterial activity of zinc oxide nanoparticle against carbapenem-resistant Acinetobacter baumannii. Front Microbiol. 2018;9:1218. doi:10.3389/ fmicb.2018.01218 